\title{
Occurrence of B chromosomes in Tetragonisca Latreille, 1811 (Hymenoptera, Apidae, Meliponini): A new contribution to the cytotaxonomy of the genus
}

\author{
Adriane Barth ${ }^{1}$, Anderson Fernandes ${ }^{2}$, Silvia das Graças Pompolo ${ }^{3}$ and Marco Antônio Costa ${ }^{1}$ \\ ${ }^{1}$ Departamento de Ciências Biológicas, Universidade Estadual de Santa Cruz, Ilhéus, BA, Brazil. \\ ${ }^{2}$ Departamento de Ciências Biológicas, Universidade do Estado de Mato Grosso, Tangará da Serra, \\ MT, Brazil. \\ ${ }^{3}$ Departamento de Ciências Biológicas, Universidade Federal de Viçosa, Viçosa, MG, Brazil.
}

\begin{abstract}
Tetragonisca angustula and Tetragonisca fiebrigi have recently been listed as valid species. This study aimed to cytogenetically investigate both species, emphasizing the new registry of B chromosomes in the tribe Meliponini. We analyzed colonies of $T$. angustula and $T$. fiebrigi collected at Tangará da Serra, Mato Grosso, Brazil, through conventional Giemsa staining, C-banding, and base-specific fluorochrome staining $\left(\mathrm{CMA}_{3} / \mathrm{DAPI}\right)$. T. angustula showed $2 n=34$ chromosomes in females and $n=17$ in males, with karyotype formula $2 \mathrm{~K}=34 \mathrm{~A}^{\mathrm{M}}$. T. fiebrigi showed numeric variation, with chromosome number varying from $2 n=34$ to $2 n=36$ in females and from $n=17$ to $n=18$ in males, with karyotype formula $2 \mathrm{~K}=32 \mathrm{~A}^{\mathrm{M}}+2 \mathrm{~A}^{\mathrm{Mc}}$ and $2 \mathrm{~K}=32 \mathrm{~A}^{\mathrm{M}}+2 \mathrm{~A}^{\mathrm{Mc}}+1$ or $2 \mathrm{~B}$-chromosomes. The $\mathrm{B}$ chromosomes are heterochromatic. In T. fiebrigi, the $\mathrm{CMA}_{3} / \mathrm{DAPI}$ staining revealed four chromosomes with a $\mathrm{CMA}_{3}$ positive band. All individuals from the same colony showed the same number of $B$ chromosomes. $T$. angustula and $T$. fiebrigi showed karyotype divergence, principally due to the presence of B chromosomes, which are found only in T. fiebrigi. Our data corroborate the status of valid species for both $T$. angustula and $T$. fiebrigi, as recently proposed.
\end{abstract}

Key words: stingless bees, cytogenetics, interspecific differentiation, B chromosomes.

Received: February 2, 2010; Accepted: June 21, 2010.

Until recently, the genus Tetragonisca comprised two species, Tetragonisca weyrauchi and Tetragonisca angustula, the latter with two subspecies: Tetragonisca angustula angustula and Tetragonisca angustula fiebrigi. Moure et al. (2007) considered both subspecies as distinct species (Tetragonisca angustula and Tetragonisca fiebrigi), based on their morphological characteristics and sympatric distribution.

Tetragonisca angustula (Latreille, 1811) has a wide geographical distribution in the Americas, from Southern Mexico to the southernmost state of Rio Grande do Sul in Brazil (Schwarz, 1938; Moure et al., 2007). This species, characterized by the black mesopleura, has been reported in all regions of Brazil (Nogueira-Neto, 1970; Moure et al., 2007). Tetragonisca fiebrigi (Schwarz, 1938) differs morphologically from $T$. angustula in the ferruginous coloration of the mesopleura and lateral areas of the propodeum. This species ranges from the state of Rio Grande do Sul to the state of Mato Grosso, according to Schwarz (1938). But this distribution range has expanded to the northwestern border with Uruguay (Schwarz, 1938) and to the state of Goiás (Oliveira et al., 2004).

Send correspondence to Marco Antônio Costa. Departamento de Ciências Biológicas, Universidade Estadual de Santa Cruz, 45662-000 Ilhéus, BA, Brazil. E-mail: costama@uesc.br.
The validity of infraspecific taxa has been particularly debated over the last 50 years, with statements of some authors favorable to it (Wilson and Brown, 1953; Smith et al., 1997; Isaac et al., 2004) and others against it (Mayr 1982; Burbrink et al., 2000; Ward, 2007). The need to use non-morphological characters for the study of subspecies was raised by Mayr (1982), referring to ecological and behavioral characteristics. On the other hand, the ambiguity of some morphological characters in species recognition, such as color pattern, has been demonstrated with molecular data (Burbrink et al., 2000).

The occurrence of $\mathrm{B}$ chromosomes is regarded as one of the sources of numerical variation in the karyotype of some species. B chromosomes are rare in Meliponini bees, and have been reported to date in Partamona helleri (Costa et al., 1992; Brito et al. 1997; Tosta et al., 2004; Martins et al., 2009) and Melipona quinquefasciata (Marla P. Rocha, personal communication).

This study was aimed at obtaining new cytogenetic information for Tetragonisca angustula and Tetragonisca fiebrigi, with emphasis on the new occurrence of B chromosomes in the tribe Meliponini.

We analyzed 20 individuals per colony, in 11 colonies of Tetragonisca fiebrigi and three colonies of 
Tetragonisca angustula, collected in Tangará da Serra, in

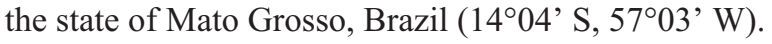

Metaphasic chromosomes were obtained from cerebral ganglia of prepupae following the method described by Imai et al. (1988). The slides were then submitted to conventional Giemsa staining, C-banding (Pompolo and Takahashi, 1990), and base-specific fluorochrome staining $\left(\mathrm{CMA}_{3} / \mathrm{DAPI}\right)$ (Schweizer, 1976). The slides were analyzed and the best metaphases were photographed using an Olympus photomicroscope. Karyotypes were arranged in decreasing order of length of euchromatic arms. Chromosome nomenclature followed Imai (1991), with pseudoacrocentric chromosomes showing an extraordinarily elongated heterochromatic short $\operatorname{arm}\left(\mathrm{A}^{\mathrm{M}}\right)$, acrocentric with totally heterochromatic arms $\left(\mathrm{A}^{\mathrm{h}}\right)$, and pseudoacrocentric with pericentromeric heterochromatin $\left(\mathrm{A}^{\mathrm{Mc}}\right)$.

We found chromosome numbers $2 \mathrm{n}=34$ in females and $\mathrm{n}=17$ in males of Tetragonisca angustula species. C-banding revealed heterochromatin in one arm of all chromosomes, and karyotypic formula $2 \mathrm{~K}=34 \mathrm{~A}^{\mathrm{M}}$ (Figure $1 \mathrm{~A}$, B). $\mathrm{CMA}_{3} / \mathrm{DAPI}$ showed no evident differential staining in chromosomes of this species (Figure $2 \mathrm{~A}, \mathrm{~B}$ ).

Tetragonisca fiebrigi showed variation in diploid chromosome number with $2 \mathrm{n}=34$ (one colony), $2 \mathrm{n}=35$ (eight colonies), and $2 n=36$ (two colonies) (Figure 1 C, D). In three of the colonies in which we found females with $2 \mathrm{n}=35$, we also found males with $\mathrm{n}=18$.

The differences in diploid number observed in these colonies ( $2 n=34$ to $2 n=36$ ) were due to the presence of up to two $\mathrm{B}$ chromosomes per individual. The length of the $\mathrm{B}$ chromosome (about $5 \mu \mathrm{m}$ ) was similar to that of the regular complement, and was observed in all individuals of the same colony.

C-banding revealed that most chromosomes of $T$. fiebrigi were pseudoacrocentric with karyotype formulae $2 \mathrm{~K}=32 \mathrm{~A}^{\mathrm{M}}+2 \mathrm{~A}^{\mathrm{Mc}}, 2 \mathrm{~K}=32 \mathrm{~A}^{\mathrm{M}}+2 \mathrm{~A}^{\mathrm{Mc}}+1 \mathrm{~B}$, and $2 \mathrm{~K}=32 \mathrm{~A}^{\mathrm{M}}+$ $2 \mathrm{~A}^{\mathrm{Mc}}+2 \mathrm{~B}$. B chromosomes were entirely heterochromatic $\mathrm{A}^{\mathrm{h}}$ (Figure 1D). Four $\mathrm{CMA}_{3}$ positive bands were also observed in two chromosome pairs, one in the interstitial region, and one in the terminal region (Figure $2 \mathrm{C}, \mathrm{D}$ ).

Although B chromosomes are frequently found in natural populations of animals and plants, they have been poorly studied in Hymenoptera. In the stingless bee Partamona helleri, B chromosomes have been reported to vary from none to four minute chromosomes per specimen (Costa et al., 1992; Brito et al., 1997; Tosta et al., 2004). Recently, Martins et al. (2009) described the occurrence of a new B chromosome in this species, larger in size than those previously reported. In Melipona quinquefasciata, up to four B chromosomes have been observed (Marla P. Rocha, personal communication).

In the ant Camponotus sp, the occurrence of up to three small B chromosomes has been reported (Mariano et al., 2001). In the wasp Nasonia vitripennis, a small submetacentric and heterochromatic B chromosome called

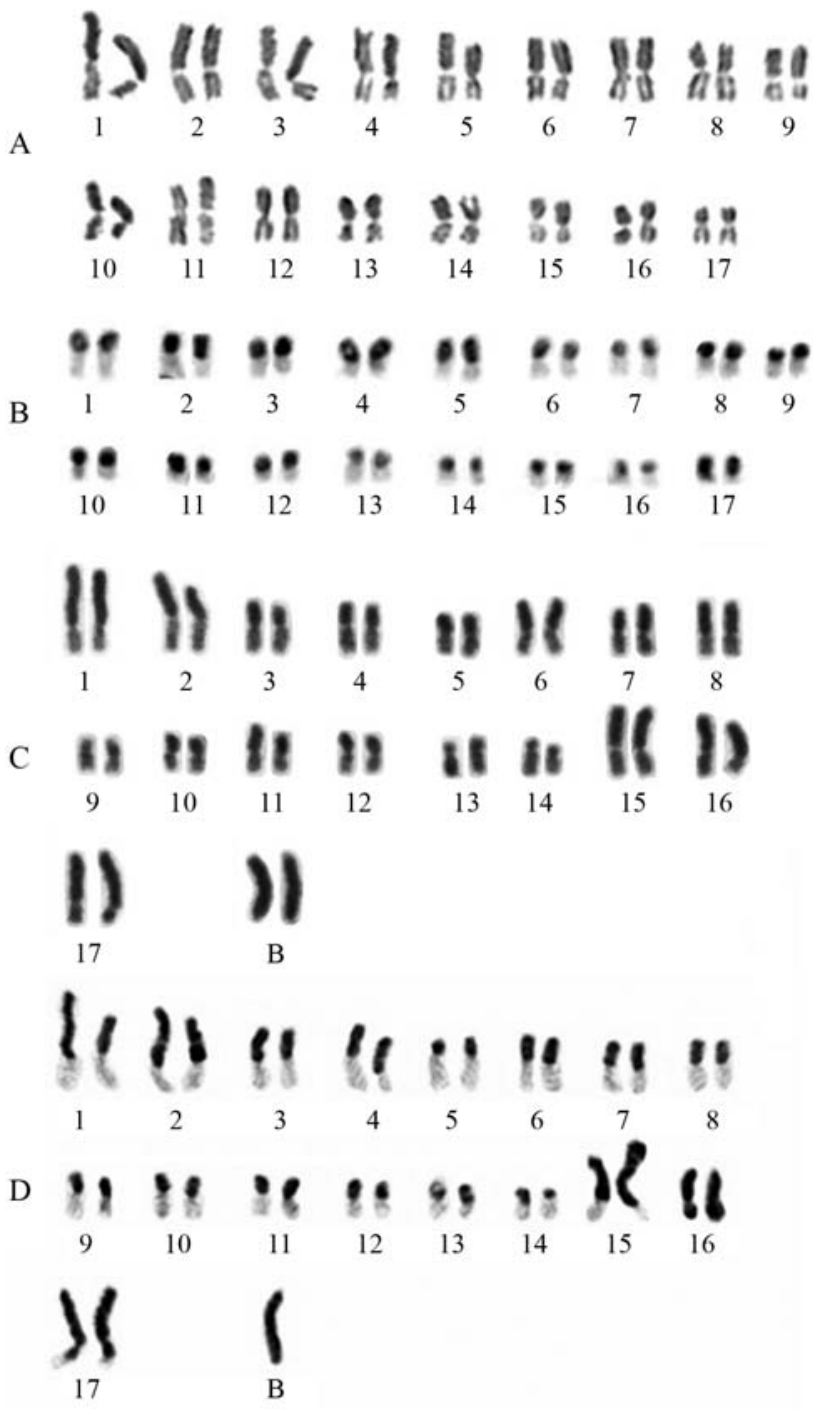

Figure 1 - Female karyograms. A) T. angustula submitted to conventional Giemsa staining. B) T. angustula submitted to C-banding. C) T. fiebrigi submitted to Giemsa staining showing two B-chromosomes. D) T. fiebrigi submitted to C-band staining showing one B chromosome.

"psr chromosome" was reported to be involved in the elimination of the paternal chromosome set in fertilized eggs, converting them into haploid eggs (Nur et al., 1988). The wasp Trypoxylon albitarse showed a constant distribution pattern of $\mathrm{B}$ chromosomes among individuals, with one and two B chromosomes in males and females, respectively (Rocha-Sanchez and Pompolo, 2004). In this case, the authors suggested that the B chromosome behaves as a chromosome of the regular complement during meiosis, undergoing balanced segregation at the end of cell division. A similar mechanism could explain the constant distribution of B chromosomes in T. fiebrigi.

In the colonies of $T$. angustula and T. fiebrigi we studied, karyotypes were distinct and conserved within each species, and no hybrid karyotypes were detected. This differentiation suggests reproductive isolation, which is reinforced by the presence of $\mathrm{B}$ chromosomes and specific 


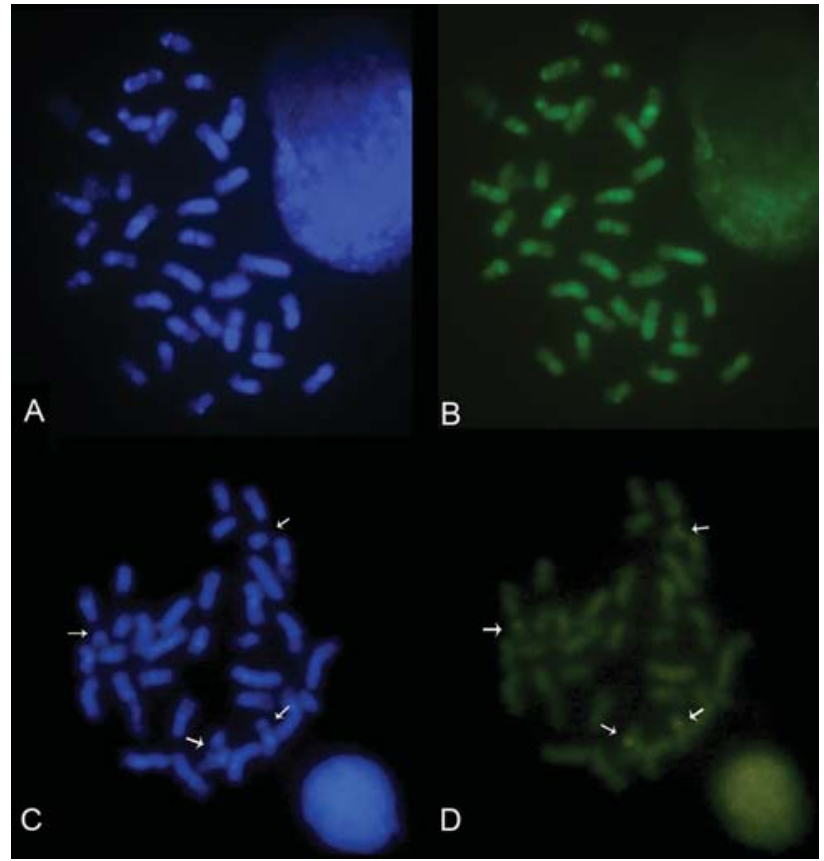

Figure 2 - Female metaphases of A and B) T. angustula submitted to DAPI and $\mathrm{CMA}_{3}$ staining, respectively, and $\mathrm{C}$ and D) T. fiebrigi submitted to DAPI and $\mathrm{CMA}_{3}$ staining, respectively. Arrows in T. fiebrigi metaphases indicate positive $\mathrm{CMA}_{3}$ bands.

$\mathrm{CMA}_{3}$ bands only in T. fiebrigi species, allowing the use of these features as cytological markers to karyotipically distinguish the two species.

Our cytogenetic data corroborate the specific status of Tetragonisca angustula and Tetragonisca fiebrigi proposed by Moure et al. (2007). The numerical constancy of colonies with B chromosomes, however, demands more investigation to elucidate if the predominance of $\mathrm{B}$ chromosomes in the progeny of $T$. fiebrigi has been favored by events such as meiotic drive.

\section{Acknowledgments}

We thank UNEMAT, FAPEMAT, and CNPq for technological and financial support and Dr. Favísia de Oliveira Freitas for the identification of the specimens.

\section{References}

Brito RM, Costa MA and Pompolo SG (1997) Characterization and distribution of supernumerary chromosomes in 23 colonies of Partamona helleri (Hymenoptera, Apidae, Meliponinae). Rev Bras Genet 20:185-188.

Burbrink FT, Lawson R and Slowinski JB (2000) Mitochondrial DNA phylogeography of the polytypic North American rat snake (Elaphe obsoleta): A critique of the subspecies concept. Evolution 54:2107-2118.

Costa MA, Pompolo SG and Campos LAO (1992) Supernumerary chromosomes in Partamona cupira (Hymenoptera, Apidae, Meliponinae). Rev Bras Genet 15:801-806.

Imai HT, Taylor RW and Crozier RH (1988) Modes of spontaneous chromosomal mutation and karyotypic evolution in ants with reference to the minimun interacion hypothesis. Jpn J Genet 63:159-185.

Imai HT (1991) Mutability of constitutive heterochromatin (cbands) during eukaryotic chromosomal evolution and their cytological meaning. Jpn J Genet 66:635-66.

Isaac NJB, Mallet J and Mace GM (2004) Taxonomic inflation: Its influence on macroecology and conservation. Trends Ecol Evol 19:464-470.

Mariano CFS, Pompolo SG, Delabie JHC and Campos LAO (2001) Estudos cariotípicos de algumas espécies neotropicais de Camponotus Mayr (Hymenoptera, Formicidae). Rev Bras Entomol 45:267-274.

Martins CCC, Duarte OMP, Waldschmidt AM, Alves RMO and Costa MA (2009) New occurrence of B chromosomes in Partamona helleri (Friese, 1900) (Hymenoptera, Meliponini). Genet Mol Biol 32:782-785.

Mayr E (1982) Of what use are subspecies? Auk 99:593-595.

Moure JS, Urban D and Melo GAR (2007) Catalogue of Bees (Hymenoptera, Apoidea) in the Neotropical Region. Sociedade Brasileira de Entomologia, Curitiba, 1058 pp.

Nogueira-Neto P (1970) A Criação de Abelhas Indígenas Sem Ferrão. 2nd edition. Tecnapis, São Paulo 365 pp.

Nur U, Werren JH, Eickbush D, Burke W and Eickbush T (1988) A "selfish" B chromosome that enhances its transmission by eliminating the paternal chromosomes. Science 240:512-514.

Oliveira RC, Nunes FMF, Campos APS, Vasconcelos SM, Roubik D, Goulart LR and Kerr WE (2004) Genetic divergence in Tetragonisca angustula Latreille, 1811 (Hymenoptera, Meliponinae, Trigonini) based on RAPD markers. Genet Mol Biol 27:181-186.

Pompolo SG and Takahashi CS (1990) Chromosome numbers and $\mathrm{C}$ banding in two species of the genus Polistes (Hymenoptera, Polistinae, Polistinii). Insectes Soc 37:251-257.

Rocha-Sanchez SMS and Pompolo SG (2004) Imitate to integrate: Reviewing the pathway for B chromosome integration in Trypoxylon (Trypargilum) albitarse (Hymenoptera, Sphecidae). Cytogenet Genome Res 106:398-401.

Schwarz HF (1938) The stingless bees (Meliponidae) of British Guianaand some related forms. Bull Am Mus Nat Hist 74:437-508.

Schweizer D (1976) Reverse fluorescent chromosome banding with chromomycin and DAPI. Chromosoma 58:307-324.

Smith H, Chiszar D and Montanucci R (1997). Subspecies and classification. Herpetol Rev 28:13-16.

Tosta VC, Fernandes-Salomão M, Tavares MG, Pompolo SG, Barros RG and Campos LAO (2004) A RAPD marker associated with B chromosome in Partamona helleri (Hymenoptera, Apidae). Cytogenet Genome Res 106:279-283.

Ward PS (2007) Edward O. Wilson and his contributions to ant systematics, In: Snelling RR, Fisher BL and Ward PS (eds). Advances in Ant Systematics (Hymenoptera, Formicidae): Homage to E. O. Wilson - 50 Years of Contributions. Memoirs of the American Entomological Institute, Gainesville. pp 3-7.

Wilson EO and Brown Jr WL (1953). The subspecies concept and its taxonomic application. Syst Zool 2:97-111.

Associate Editor: Yatiyo Yonenaga-Yassuda

License information: This is an open-access article distributed under the terms of the Creative Commons Attribution License, which permits unrestricted use, distribution, and reproduction in any medium, provided the original work is properly cited. 